\title{
Characterization of the atmospheric component of the winter hydrological cycle in the Galicia/North Portugal Euro-region: a Lagrangian approach
}

\author{
Anita Drumond ${ }^{1, *}$, Raquel Nieto ${ }^{1}$, Luis Gimeno ${ }^{1}$, Sergio M. Vicente-Serrano ${ }^{2}$, \\ Juan I. López-Moreno ${ }^{2}$, Enrique Morán-Tejeda ${ }^{2}$
}

${ }^{1}$ EPhysLab, Departamento de Física Aplicada, Facultade de Ciencias, Universidade de Vigo, Ourense 32004, Spain

${ }^{2}$ Instituto Pirenaico de Ecología, CSIC, Zaragoza 50080, Spain

\begin{abstract}
The Lagrangian 3-dimensional FLEXPART model was used to investigate the main sources of moisture for the Galician/northern Portugal (GALNP) region, as well as their inter-annual variability during winter. FLEXPART identifies humidity contributions to the moisture budget over a region through the computation of changes in the specific humidity along backward trajectories of up to $10 \mathrm{~d}$. Two analyses were done for the period between 1990/1991 and 1998/1999: the first considering all winter days and the second only precipitation days over GALNP. Two dominant source regions of moisture were detected: the extended Bay of Biscay (BB) and the Tropical and Subtropical North Atlantic corridor (TSNA). The BB presented a large $1 \mathrm{~d}$ maximum and a very significant contribution in the period from 1 to $4 \mathrm{~d}$ backward. The TSNA only showed a net uptake of moisture for GALNP from $2 \mathrm{~d}$ backward, and its contribution reached a maximum on the 5th day backward. The results suggest that the inter-annual variations in winter precipitation over GALNP could be directly associated with the variability observed in the contribution of moisture from the TSNA. A large part of the contribution of moisture from the BB occurs during anticyclonic conditions over the GALNP region, which relate to stable atmospheric conditions and the inhibition of precipitation. On the other hand, around $75 \%$ of the total TSNA winter contribution occurred during precipitation days. Once dynamic conditions are favourable for generating precipitation, it appears that there is some contribution from the $\mathrm{BB}$ to precipitation days in the GALNP region.
\end{abstract}

KEY WORDS: Moisture sources · Lagrangian methodology $\cdot$ North-western Iberian Peninsula

\section{INTRODUCTION}

The so-called Euro-region Galicia/northern Portugal ( 41 to $44^{\circ} \mathrm{N}, 9$ to $6.5^{\circ} \mathrm{W}$; hereafter GALNP) covers the north-western part of the Iberian Peninsula over the territories of Spain and Portugal (Fig. 1a). It is surrounded by the Atlantic Ocean and the Cantabrian Sea. In general, the coastal and adjacent areas are characterized by a maritime climate with mild summers and rainy winters, while the interior part of the region is characterized by a continental climate with warm summers and cold winters. However, its geographical location and particular orography increase the complexity of climate studies, as discussed by Gómez-Gesteira et al. (2010) in a detailed review of the climate observed in the GALNP region during the 20th century.

Gómez-Gesteira et al. (2010) commented that GALNP lies in the mid-latitude belt of the Atlantic region and the precipitation regime is strongly affected by the mean annual cycle of the location of the Atlantic storm track and its deviations. The prevailing western circulation directs the oceanic air masses inland. Thus, stronger western advection brings milder and wetter weather and stronger winds, especially in autumn and winter. In summer, however, quasi-stationary cyclones 
over heated land masses with little precipitation are mostly dominant over Iberia (e.g. Trigo et al. 1999). According to Ramos et al. (2010) and the references therein, variability modes of the atmosphere can also affect local climate variability, e.g. the North Atlantic Oscillation (NAO), the Scandinavian pattern (SCAND), the Eastern Atlantic (EA), and the Eastern Atlantic/ Western Russia (EA/WR) (see Barnston \& Livezey 1987 for descriptions of the main atmospheric variability modes). Furthermore, the Iberian Peninsula is located at the southern margin of the Atlantic tropospheric river (Zhu \& Newell 1998), the main large-scale feature providing moisture at Atlantic mid-latitudes.

According to Brubaker et al. (1993), precipitation that falls in a region has 1 of 3 origins: (1) moisture already present in the atmosphere, (2) moisture advected into the region by wind, or (3) evaporation from the surface below (corresponding to the recycling component). Averaged over long periods, the major processes responsible for the observed atmospheric moisture are local evaporation (recycling) and transport from remote sources (advection).

Several methodologies have been used to identify the sources of geographical moisture for different regions (e.g. Eltahir \& Bras 1996, Chen et al. 1994, Crimp \& Mason 1999, Numaguti 1999), almost all of them following Eulerian techniques. More sophisticated approaches have been developed recently based on the use of fully kinematic trajectories calculated from different Lagrangian particle models, e.g. the methodology developed by Stohl \& James $(2004,2005)$. In their model, known as FLEXPART, the net water changes are diagnosed along a large number of back trajectories, enabling inferences to be made about the moisture sources in a region.
The origin of the moisture observed in GALNP has not been fully investigated. Recently, Gimeno et al. (2010) studied the main climatological sources of moisture in the atmosphere over the whole Iberian Peninsula at annual and seasonal scales using FLEXPART for the period from 2000 to 2004. The 2 most important moisture sources affecting the region are (1) the tropical-subtropical North Atlantic corridor and (2) the peninsula itself and western Mediterranean, with their relative importance varying throughout the year and among different regions. While the former region is the dominant source for the entire Iberian Peninsula during winter and in western regions throughout the year, the latter area dominates the moisture supply to the Iberian Peninsula in summer and in the eastern Mediterranean region of the peninsula throughout the year.

In the present paper we extend the Gimeno et al. (2010) study focussed on the north-western Iberian Peninsula to a 9 yr period, developing a detailed characterization of the main sources of moisture for the GALNP region during winter, as well as aspects of their inter-annual variability through a updated FLEXPART version forced by reanalysis data. In this methodology, the 'sources of moisture' are defined as those regions crossed by the air masses in transit towards the study area and where there is a predominance of evaporation over precipitation. Moreover, all air particles identified in the target region, even the non-precipitating ones, would be tracked backward. Reinforcing the robustness of this work, it is worth noting that the methodology proposed here has already been successfully applied in climatological studies of moisture sources in other regions, including the Sahel (Nieto et al. 2006), Iceland (Nieto et al. 2007), the a)

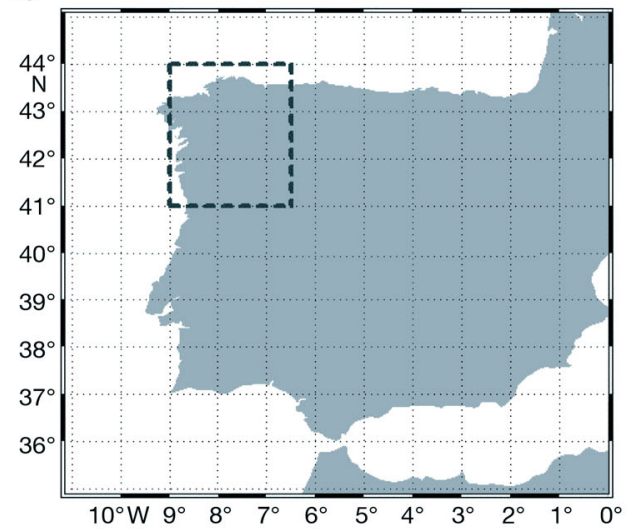

b) $E-P\left(10^{-1} \mathrm{~mm} \mathrm{~d}^{-1}\right)$

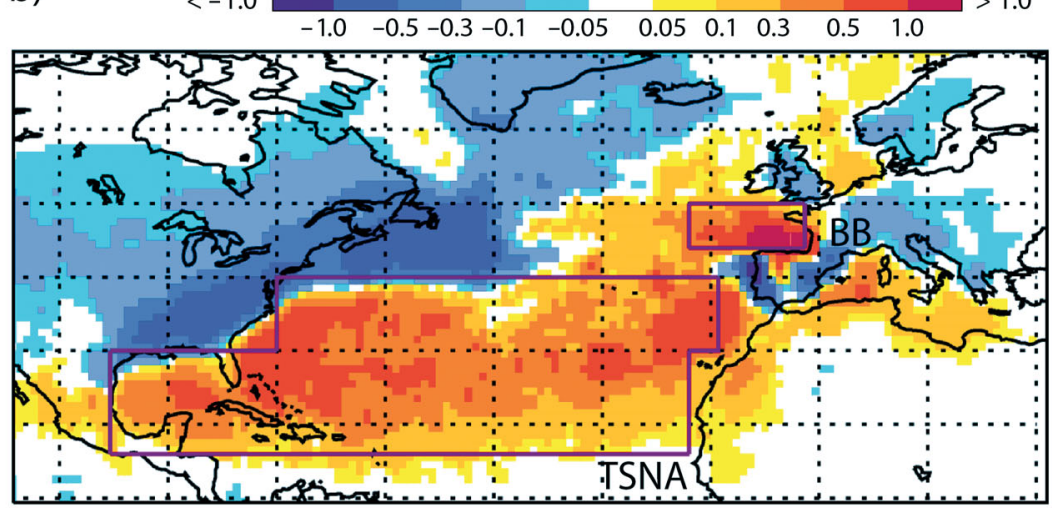

Fig. 1. (a) Area (Galicia/northern Portugal; GALNP) used to compute trajectories (rectangle). (b) Average winter (DJF) values of 10 d integrated evaporation-precipitation $(E-P)$ for the period from 1990/1991 to 1998/1999 for all particles bound for the GALNP region during all winter days, determined from backward tracking. Values are plotted $\times 10^{-1}$ per millimetre per day. The purple polygons in the annual field indicate the main oceanic source regions for GALNP moisture: the tropical-subtropical North Atlantic (TSNA, larger) and the extended Bay of Biscay (BB, smaller) 
Orinoco River basin (Nieto et al. 2008), the South American monsoon system (Drumond et al. 2008) and the Mediterranean region (Nieto et al. 2010).

The data, model and methodology are described in Section 2. Section 3 shows the results for the trajectory analyses divided into 2 subsections: the first considers all winter days, while the second considers only precipitation days. Comparing these can reveal aspects of the contribution of moisture to the effective generation of precipitation. The main results are summarized in Section 4.

\section{DATA AND METHODOLOGY}

To determine the sources of moisture our study was based on the method developed by Stohl \& James (2004, 2005), which used the Lagrangian particle dispersion model FLEXPART. Version 8.0 of this model, forced by the ERA40 reanalysis data set (Uppala et al. 2005), was used to track different meteorological parameters for the entire atmosphere along trajectories. As we are interested in atmospheric moisture, the equivalent humidity interpolated to the position of the trajectory at a given time was used.

In order to identify each particle trajectory, the atmosphere is divided homogeneously into a large number of particles at the start of the model. These particles have a constant mass and are distributed homogeneously in the atmosphere according to the distribution of atmospheric mass. In the model, these particles are advected using 3 dimensional (3-D) ERA40 winds. To calculate both the grid-scale advection, as well as the turbulent and convective transport of particles, ERA40 data were also used as input to the model. Their positions and specific humidity values $(q)$ were temporally interpolated from the input data set, which was recorded every $6 \mathrm{~h}$. The increases $(e)$ and decreases $(p)$ in moisture along the trajectory can be calculated from changes in $(q)$ with time $(e-p=m d q / d t)$, where $m$ is the mass of the particle. When adding $(e-p)$ for all the particles in the atmospheric column over an area, it is possible to obtain $(E-P)$, where the surface freshwater flux $(E)$ represents evaporation and $(P)$ is the precipitation rate per unit area. The method can also track $(E-P)$ from any specific region backwards in time along the trajectories, choosing those particles that reach the target region at the time of interest. According to Stohl \& James (2004) and Stohl et al. (2005), the limitations of the method mainly concern $q$ fluctuations along individual trajectories, which can also occur for non-physical reasons (e.g. because of $q$ interpolation or trajectory errors). Partly, such noise is compensated for among the many particles in the atmospheric column over an area.
In the present work we used the tracks of 1.9 million particles distributed all over the globe in a $9 \mathrm{yr}$ period (1990 to 1999), computed using ERA 40 reanalysis data available every $6 \mathrm{~h}$ (00:00, 06:00, 12:00 and 18:00 h UTC) at a $1^{\circ} \times 1^{\circ}$ resolution in latitude and longitude on all 60 vertical levels. $E$ - $P$ retro-trajectory analysis was performed for all air particles residing over GALNP (approximately 500 particles $\mathrm{d}^{-1}$ ) during the months related to the boreal winter (DJF; here defined as the trimester December [Year-1]-January-February [year indicated in the figures]). Following Stohl \& James (2005) and Sodemann et al. (2008), we limit the transport times to $10 \mathrm{~d}$. According to these authors, it is the average time that water vapour resides in the atmosphere (Numaguti 1999), and it is also a period over which the trajectories can be considered relatively accurate (Stohl 1998). Furthermore, Stohl \& James (2005) show in their analyses that toward the end of the $10 \mathrm{~d}$ period, the particles lose memory of their original position and moisture.

We analysed the DJF 9 yr averages in order to identify the main moisture sources configured in the winter season during this period, as well as the inter-annual variability of the moisture contribution from the selected sources. The precipitation according to the EOBS Version 3 dataset (Haylock et al. 2008) from the EU-FP6 project ENSEMBLES, available for Europe in a daily $0.25^{\circ}$ horizontal resolution, was used to select the precipitation days and to analyse the inter-annual variability in the precipitation over GALNP. The precipitation days were selected based on the criterion applied by Gimeno et al. (2010). Here, we consider only those days when the average precipitation value over GALNP was greater or equal to $0.2 \mathrm{~mm}$, a threshold value adopted from Gallego et al. (2006) for the Iberian Peninsula. The application of this criterion gave a total of $474 \mathrm{~d}$ during winter of the 9 yr study period.

\section{RESULTS}

\subsection{Backward analysis considering all winter days}

In order to identify the major sources of moisture during the winter, Fig. 1b shows the DJF $10 \mathrm{~d}$ integrated $E-P$ values obtained from averages of $9 \mathrm{yr}$ period. Despite the relative complexity of the backtracking method, these fields provide a good representation of source and sink regions of moisture from particles in transit to the area of study. In those reddish regions characterized by $E-P>0$, evaporation dominated over precipitation, which indicates that air particles destined for the GALNP region in that vertical column gained moisture; such regions were therefore designated as moisture source regions. On the other 
hand, air masses in transit to GALNP over bluish regions, where precipitation dominated over evaporation $(E-P<0)$, had a net loss of moisture; these were designated moisture sink regions. Fig. 1b indicates that there are 2 dominant oceanic moisture source regions for GALNP: the extended Bay of Biscay (hereafter BB) and the Tropical and Subtropical North Atlantic corridor (hereafter TSNA), this latter region extending from the Gulf of Mexico to Africa, from 16 to $40^{\circ} \mathrm{N}$. The importance of the TSNA as a moisture source has already been reported by Gimeno et al. (2010) for the Iberian Peninsula, as well as in studies of other western Europe regions at higher latitudes (Nieto et al. 2007, Sodemann et al. 2008). According to these authors, this source is probably associated with tropospheric rivers, which are also related to the extratropical cyclones responsible for most of the precipitation on the western side of the extratropical continental latitudes (Ralph et al. 2004, Bao et al. 2006).

To evaluate the relative importance of the 2 sources of moisture to the atmosphere overlying the GALNP region in winter, water vapour transport was assessed by quantifying the $(E-P)_{\mathrm{n}}$ series (n varying from the 1 st to 10th day) calculated backward for the target region and integrated over the 2 source areas (the purple polygons indicated in the DJF $E-P$ field shown in Fig. 1b). We followed the same procedure adopted by Gimeno et al. (2010), but the spatial limits of the TSNA were slightly different from the ones they used, since our $E$ - $P$ results may have differed from theirs as we were considering different target areas, data periods (they analysed data from 2000 to 2004), model versions and input datasets. In any case, the general $E-P$ patterns were very similar. Fig. 2 shows the DJF time series (averages of the $9 \mathrm{yr}$ period) of relative values of $(E-P)_{\mathrm{n}}$ for the $\mathrm{BB}$ and TSNA regions, taking into account the area of each source. These indicate that the $\mathrm{BB}$ presented a large $1 \mathrm{~d}$ maximum and a very significant contribution in the period from 1 to $4 \mathrm{~d}$ backward. The TSNA only had a net uptake of moisture for GALNP from 2 d backward, and its maximum winter moisture supply occurred 5 d backward. Comparing the absolute magnitude of the values presented by both regions (data not presented), the contribution from the TSNA is larger than that presented by the BB, possibly due to the larger area considered for the analysis. However, the relative importance of the BB as a moisture source is revealed when considering the source areas (each series was divided by the area of its respective source), as we can see from the $10 \mathrm{~d}$ integrated $(E-P)_{\mathrm{n}}$ values (Fig. 2). In agreement with our results, Gimeno et al. (2010) have also reported the importance of the TSNA in providing moisture for the north-western Iberian Peninsula, particularly during winter.

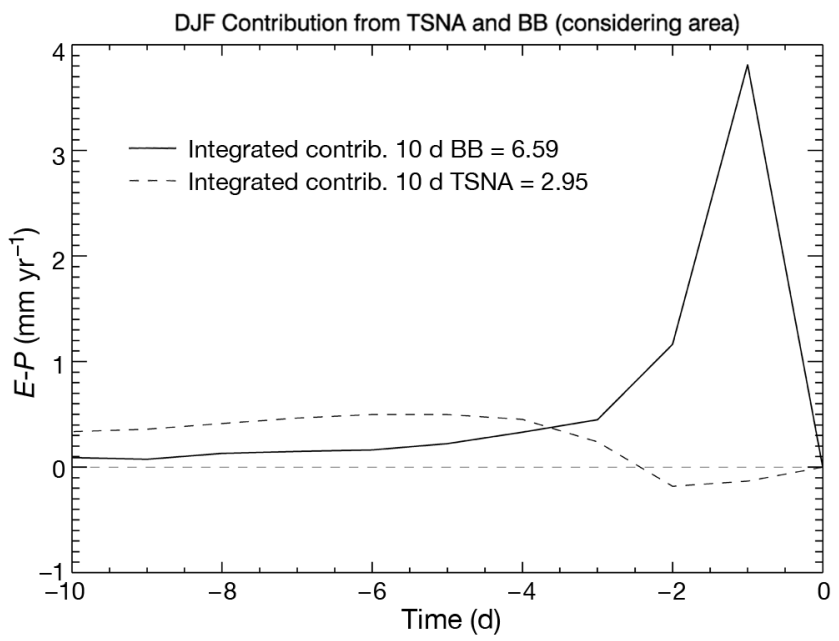

Fig. 2. Winter (DJF) time series of evaporation-precipitation series (n varying from the 1 st to 10 th day) $(E-P)_{\mathrm{n}}$, calculated backward for moisture over Galicia/northern Portugal (GALNP), integrated over the extended Bay of Biscay (BB; continuous line) and the Tropical-Subtropical North Atlantic (TSNA; broken line). These series represent relative values of $(E-P)_{\mathrm{n}}$ taking into account the area of each source region; the units are millimetre per year.

The inter-annual variability of the DJF $10 \mathrm{~d}$ integrated $E-P$ contribution of both moisture sources was assessed for the period from 1990/1991 to 1998/1999 and is presented in Fig. 3; the temporal evolution of GALNP precipitation is also plotted on the same figure, and we examined possible associations between it and the inter-annual variability. Each time series is normalized by its respective maximum value, observed in the period in question, in order to facilitate comparison. As seen in Fig. 3, the maximum values of GALNP precipitation and the TSNA contribution were observed in the winter of 1995/1996. On the other hand, the maximum BB contribution observed in the winter of 1998/1999 coincides with one of the lowest precipitation values for the GALNP region. Moreover, Fig. 3 suggests that the inter-annual variability in the contribution from the TSNA follows a temporal evolution similar to that presented by winter precipitation, confirmed by the high correlation coefficient of 0.88 (statistically significant at the $99 \%$ level by Student's $t$-test considering 7 degrees of freedom), in contrast to the low negative coefficient of -0.17 between the contribution of the BB and precipitation time series.

To better understand the dynamic conditions associated with the contributions of different sources, as well as whether these conditions are favourable for precipitation over GALNP, an analysis of the inter-annual variability in the frequency of different weather types (WT) observed over the north-western Iberian Peninsula was also carried out (Fig. 3). A detailed climatological discussion of the dominant atmospheric circula- 


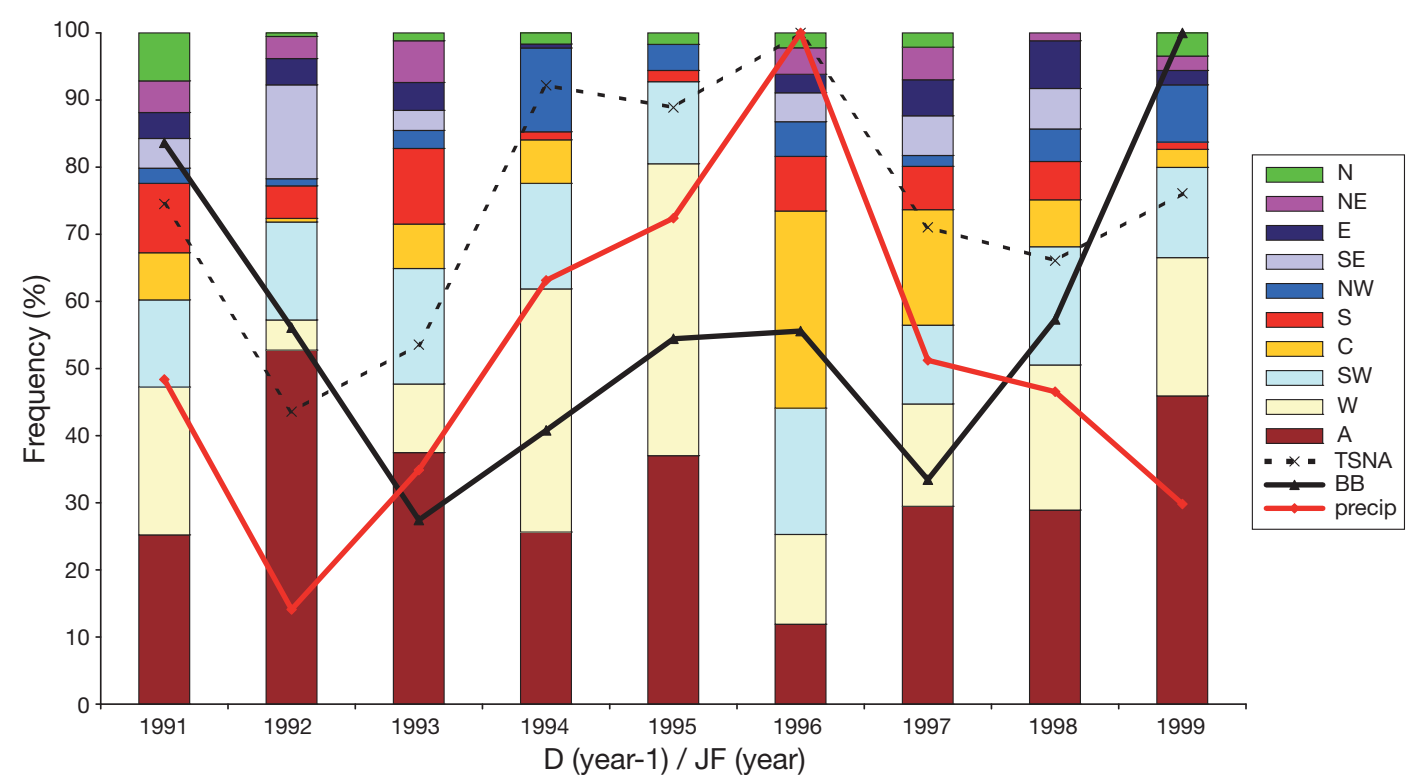

Fig. 3. Time series of winter (DJF) accumulated precipitation averaged over Galicia/northern Portugal (GALNP; red continuous line); $10 \mathrm{~d}$ integrated evaporation-precipitation $(E-P)$ calculated backward for moisture over GALNP, integrated over the extended Bay of Biscay (BB; black continuous line) and the Tropical-Subtropical North Atlantic (TSNA; black broken line), and the DJF frequency percentage of the synoptic weather type (colour bars, according to direction, key) for the period from 1990/1991 to 1998/1999. The 3 time series were normalized by the respective maximum; the values are represented in percentages. C: cyclonic; A: anticyclonic

tion patterns over the north-western Iberian Peninsula, their relation to local precipitation and the compatibility with modes of low-frequency variability can be found in the studies by Lorenzo et al. (2008) and Ramos et al. (2010), where the methodology applied to identify the WTs is also assessed. In order to illustrate the circulation patterns related to the different WTs, Fig. 4 (from Lorenzo et al. 2008) shows the annual average sea level pressure fields characteristic of the 10 basic synoptic WTs considered. Summarizing their findings, anticyclone WTs are the most frequent throughout the year, and the frequency of occurrence of western and south-western patterns is also significant in autumn and winter. In terms of precipitation, they found that cyclonic, western and south-western WTs explain most of the precipitation throughout the year, whereas northern, eastern and anticyclonic WTs are associated with drought conditions.

The results plotted in Fig. 3 indicate that the maximum contribution of $\mathrm{BB}$ values observed during the winter of 1990/1991 and 1998/1999 were associated with a higher frequency of anticyclonic and/or northern patterns. From Fig. 5 we can see that the 10 d integrated contribution from $\mathrm{BB}$, considering only winter days with a predominance of anticyclonic WTs over GALNP during the $9 \mathrm{yr}$ period, is $3.98 \mathrm{~mm} \mathrm{yr}^{-1}$. That means that almost $60 \%$ of the total contribution from the $\mathrm{BB}$ during winter days occurs under anticyclonic conditions (for comparison, the contribution from the BB considering all winter days is indicated in Fig. 2).
The anticyclonic and northern WTs are characterized by a high pressure centre established just north-west or west of the area under study, respectively, allowing that air masses travel from BB to GALNP. As Lorenzo et al. (2008) pointed out, these WTs are related to drought conditions over the area, which could mean that years presenting higher moisture contribution from the BB are associated with atmospheric stability conditions and, consequently, reduced precipitation over GALNP. The opposite seems to occur with respect to the interannual variability of the moisture contribution from the TSNA. The maximum TSNA contribution and GALNP precipitation occurring in DJF 1995/1996 coincide with a year in which the cyclonic pattern is predominant. This is characterized by a low pressure centre located in north-western GALNP that allows air masses to travel from the Atlantic towards the region. A higher moisture contribution from the TSNA, associated with an instable atmosphere, could be related to enhanced precipitation conditions over the GALNP region.

\subsection{Backward analysis considering only winter precipitation days}

In this section we report on a reanalysis of the data described in the previous section, but considering only those days when precipitation was observed in GALNP. Tracing the selected particles backward (Fig. 6) showed that $10 \mathrm{~d}$ integrated $E-P$ values were higher over the 

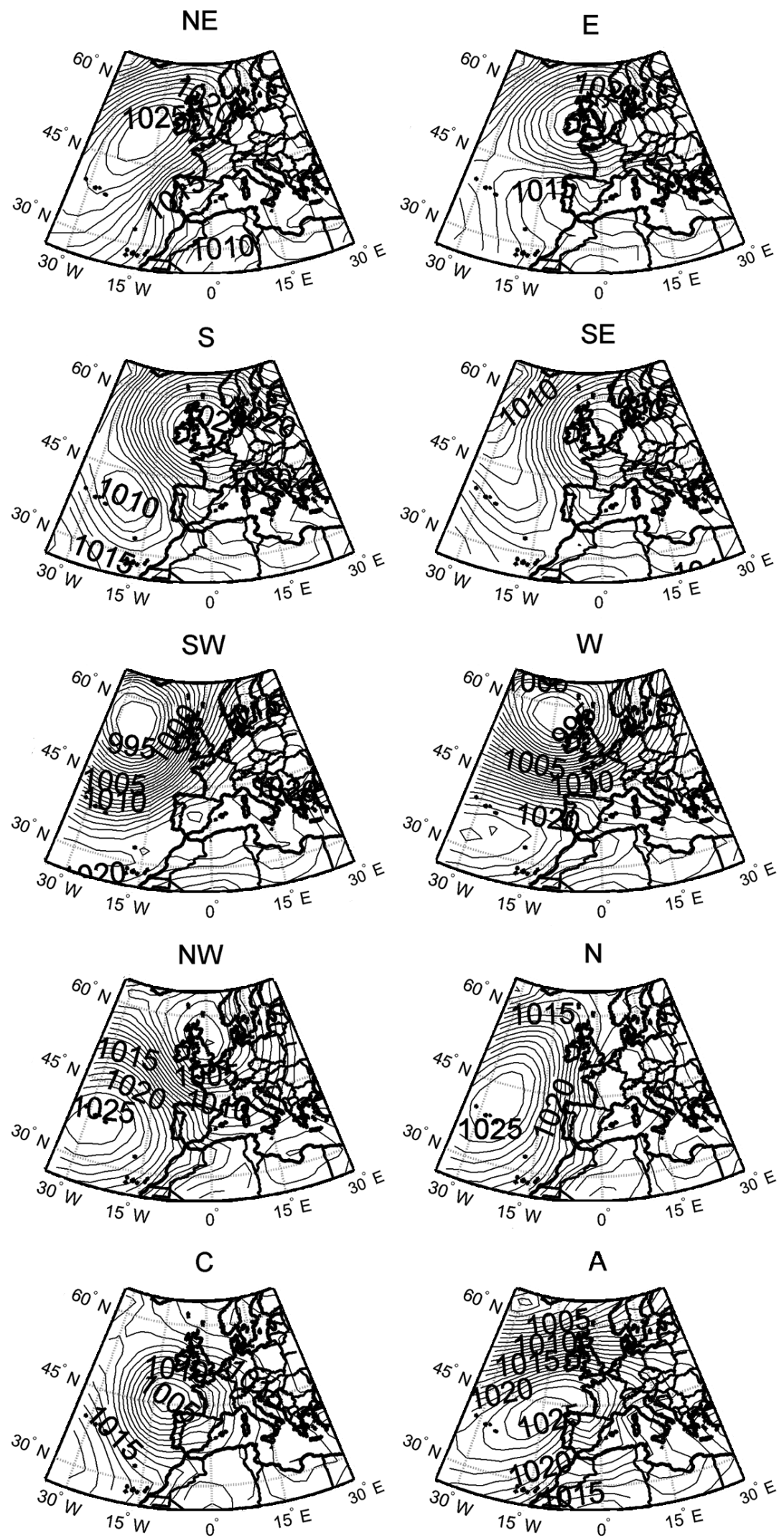

Fig. 4. Annual average sea level pressure fields characteristic of the 10 basic synoptic weather types characterized for the NW Iberian Peninsula (adapted from Lorenzo et al. 2008). C: cyclonic, A: anticyclonic
TSNA region compared to values shown in Fig. 1. Although the positive $E-P$ values were less intense over the $\mathrm{BB}$ area, another source was indicated over the North Atlantic, more precisely between 40 and $50^{\circ} \mathrm{N}$, coinciding with the Atlantic storm track region.

In order to evaluate the contribution of the BB and TSNA sources in generating effective precipitation, the analysis plotted in Fig. 2 was repeated for the same source areas, but considering only the contribution associated with the selected precipitation days. Fig. 7 shows the DJF time series (averages of the 9 yr period) of relative values of $(E-P)_{\mathrm{n}}$ for the BB and TSNA regions, taking into account the area of each source. As for the results presented in Fig. 2, the BB has a large $1 \mathrm{~d}$ maximum and a very significant contribution in the period from 1 to $4 \mathrm{~d}$ backward. The TSNA only had a net uptake of moisture for GALNP from 2 d backward, and its maximum winter moisture supply occurred $4 \mathrm{~d}$ backward. Comparing the $10 \mathrm{~d}$ integrated $(E-P)_{\mathrm{n}}$ contributions (the values indicated in Figs. 2 \& 7, top left) reveals that $75 \%$ of the total TSNA winter contribution occurred during precipitation days in contrast to $48 \%$ for the BB. Such results suggest a high association between the contribution of moisture from the TSNA and the occurrence of precipitation over the GALNP region.

Aspects of the inter-annual variability in the DJF 10 day integrated $E$-P contribution of both moisture sources and WT frequencies were also explored, considering only precipitation days in the period from 1990/1991 to 1998/ 1999. As seen in Fig. 8, the maximum values of GALNP precipitation and of the TSNA and BB contributions were observed in the winter 1995/1996, suggesting some contribution of moisture from the $\mathrm{BB}$ once dynamic conditions have developed for generating precipitation over the GALNP region. This can also be inferred from the similar temporal evolution patterns observed in the inter-annual variability of the contributions from the TSNA and BB and of winter precipitation. If we calculate 


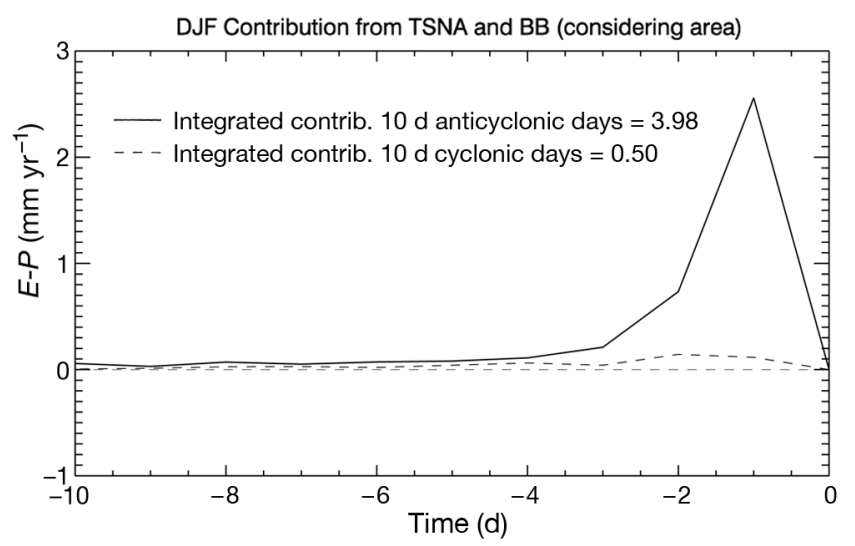

Fig. 5. Winter (DJF) time series of evaporation-precipitation series (n varying from the 1 st to 10 th day) $(E-P)_{\mathrm{n}}$ calculated backward for moisture over Galicia/northern Portugal (GALNP), integrated over the extended Bay of Biscay (BB) considering only anticyclonic (continuous line) and cyclonic days (broken line), observed from 1990/1991 to 1998/1999. These series represent relative values of $(E-P)_{\mathrm{n}}$ taking into account the area of the $\mathrm{BB}$ source region; the units are millimetres per year

the linear correlation with the precipitation time series, we obtain correlation coefficients of 0.92 and 0.59 for the TSNA and BB contributions, respectively (the first is statistically significant at the $99.9 \%$ level by Student's $t$-test, and the latter, at $90 \%$ ).

An analysis of the inter-annual variability of the different WT frequencies observed over the GALNP region is also illustrated in Fig. 8, considering only precipitation days. The maximum observed in the 3 time series during 1995/1996 coincides with the year presenting the highest frequency of cyclonic conditions in the studied period. Again, a higher contribution of the $\mathrm{BB}$ and lower precipitation observed during the winters of 1990/1991 and 1998/1999 were associated with a higher frequency of anticyclonic and/or northern weather patterns.
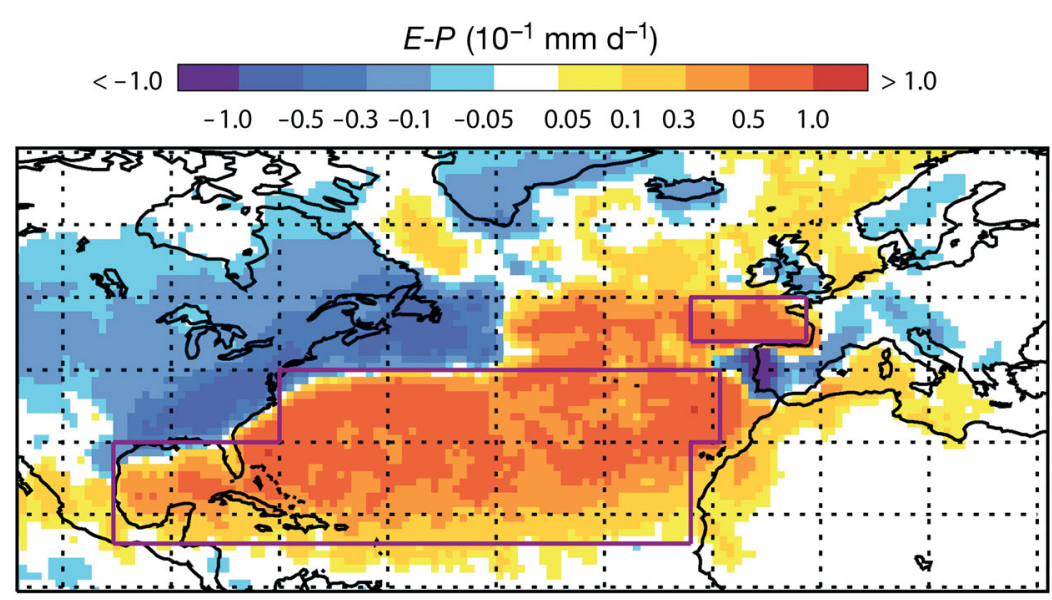

Fig. 6. Average winter values of $10 \mathrm{~d}$ integrated evaporation-precipitation $(E-P)$, as in Fig. 1b, but calculated only for the days with precipitation in GALNP

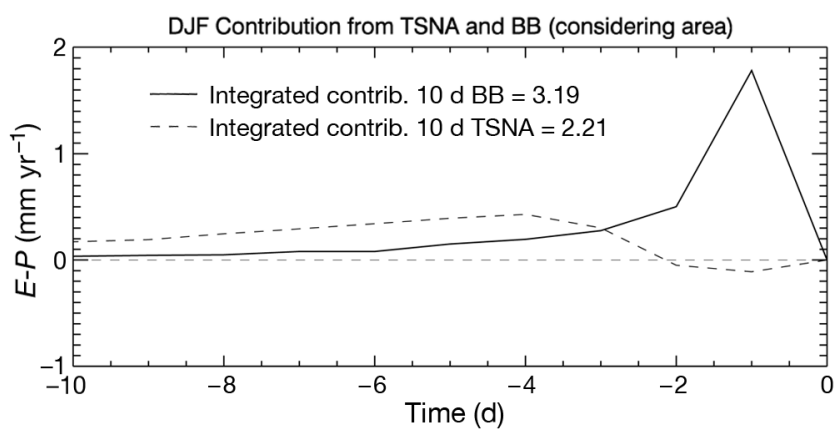

Fig. 7. Winter time-series of evaporation-precipitation series, as Fig. 2, but calculated only for the days with precipitation in GALNP

\section{CONCLUSIONS}

Using data from the Lagrangian FLEXPART Ver. 8.0 model, available for the period from 1991 to 1999, the purpose of this work was to investigate the main sources of moisture found in the GALNP region during boreal winter and to illustrate some aspects of the inter-annual variability. It is important to mention that, in this methodology, the 'sources of moisture' are defined as those regions crossed by air masses in transit towards the study area in which a predominance of evaporation over precipitation exists.

$E$-P retro-trajectory analysis was performed for all air particles residing over the GALNP region $\left(41\right.$ to $44^{\circ} \mathrm{N}$, 9 to $6.5^{\circ} \mathrm{W}$ ), limiting the transport times to $10 \mathrm{~d}$. The analysis was divided into 2 parts, the first considering all winter days and the second considering only precipitation days over GALNP. The main findings can be summarized as follows:

Two dominant moisture source regions were determined for GALNP: the extended Bay of Biscay and the Tropical and Subtropical North Atlantic corridor; the latter extends from the Gulf of Mexico to Africa, from 16 to $40^{\circ} \mathrm{N}$. The BB presented a large 1 $\mathrm{d}$ maximum and a very significant contribution in the period from 1 to $4 \mathrm{~d}$ backward. The TSNA only showed a net uptake of moisture for GALNP from 2 d backward, and its contribution reached a maximum on the 5th day backward.

It appears that the inter-annual variability of the winter contribution from the TSNA source presents a temporal time course similar to that of the winter precipitation over GALNP in the period from 1991 to 1999, according to the coincident occurrence of the respective maxima in the time series and a high correlation coefficient. An analysis of 


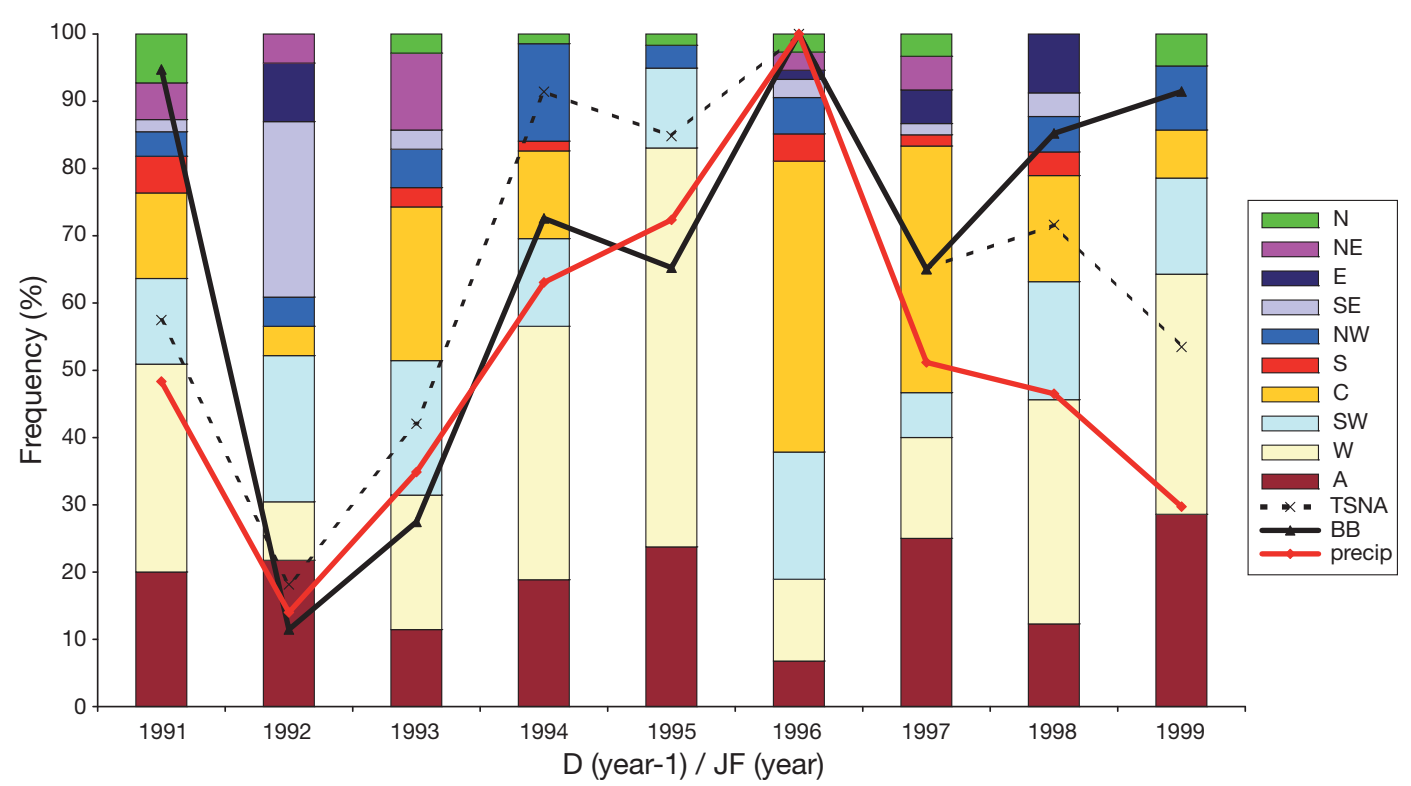

Fig. 8. Time series of winter accumulated precipitation, as Fig. 3, but calculated only for the days with precipitation in GALNP

the inter-annual variability of the frequency of occurrence of weather types over GALNP during winter showed that around $60 \%$ of the total contribution from the $\mathrm{BB}$ during winter days occurs under anticyclonic conditions associated with atmospheric stability and reduced precipitation. On the other hand, the maxima of the TSNA contribution and GALNP precipitation occurred in DJF 1995/1996, a year in which the cyclonic pattern was predominant.

Repeating the analysis only for those days when precipitation was observed in GALNP, a third source of moisture, in addition to the BB and TSNA, was revealed over the North Atlantic, more precisely between 40 and $50^{\circ} \mathrm{N}$. Around $75 \%$ of the total TSNA winter contribution occurred during precipitation days in contrast to $48 \%$ for the $\mathrm{BB}$, suggesting a high association between the contribution of moisture from the TSNA and the occurrence of precipitation over GALNP. A similar temporal evolution was observed in the inter-annual variability of the contributions from the TSNA and BB and winter precipitation, suggesting some contribution of moisture from the BB once dynamic conditions for generating precipitation over GALNP had developed.

A detailed analysis of the transportation of moisture according to different weather types is necessary for a better understanding of how sources contribute to the moisture and precipitation in the GALNP region; such an analysis will be presented elsewhere. Furthermore, the FLEXPART dataset is being extended back to 1979, to lengthen the analysis period and allow for more conclusive results on inter-annual variability.
Acknowledgements. We thank the Spanish Ministry of Science and Innovation (MCINN) for the grants CGL200805968-C02-02 and CGL2008-05968-C02-01 (M.S.M.), as well as the support provided by the Xunta de Galicia (INCITE09 383278 PR). Thanks to Dr. Nieves Lorenzo and Alexandre Ramos for providing the weather types dataset and Fig. 4. Thanks to the reviewers for their comments.

\section{LITERATURE CITED}

Bao JW, Michelson SA, Neiman PJ, Ralph FM, Wilczak JM (2006) Interpretation of enhanced integrated water vapor bands associated with extratropical cyclones: their formation and connection to tropical moisture. Mon Weather Rev 134:1063-1080

Barnston AG, Livezey RE (1987) Classification, seasonality and persistence of low-frequency atmospheric circulation patterns. Mon Weather Rev 115:1083-1126

Brubaker KL, Entekhabi D, Eagleson P (1993) Estimation of continental precipitation recycling. J Clim 6:1077-1089

Chen TC, Pfaendtner J, Weng SP (1994) Aspects of the hydrological cycle of the ocean-atmosphere system. J Phys Oceanogr 24:1827-1833

Crimp SJ, Mason SJ (1999) The extreme precipitation event of 11 to 16 February 1996 over South Africa. Meteorol Atmos Phys 70:29-42

Drumond A, Nieto R, Gimeno L, Ambrizzi T (2008) A Lagrangian identification of major sources of moisture over Central Brazil and La Plata Basin. J Geophys Res 113: D14128. doi:10.1029/2007JD009547

Eltahir E, Bras RL (1996) Precipitation recycling. Rev Geophys 34:367-378

Gallego MC, García JA, Vaquero JM, Mateos VL (2006) Changes in frequency and intensity of daily precipitation over the Iberian Peninsula. J Geophys Res 111:D24105, doi:10.1029/2006JD007280

Gimeno L, Nieto R, Trigo R, Vicente-Serrano SM, LópezMoreno JI (2010) Where does the Iberian Peninsula moisture come from? An answer based on a Lagrangian 
approach. J Hydrometeorol 11:421-436

Gómez-Gesteira M, Gimeno L, de Castro M, Lorenzo MN and others (2011) The state of climate in NW Iberia. Clim Res 48:109-144

Haylock MR, Hofstra N, Klein Tank AMG, Klok EJ, Jones PD, New M (2008) A European daily high-resolution gridded dataset of surface temperature and precipitation. J Geophys Res 113:D20119. doi:10.1029/2008JD010201

Lorenzo MN, Taboada JJ, Gimeno L (2008) Links between circulation weather types and teleconnection patterns and their influence on precipitation patterns in Galicia (NW Spain). Int J Climatol 28:1493-1505

Nieto R, Gimeno L, Trigo RM (2006) A Lagrangian identification of major sources of Sahel moisture. Geophys Res Lett 33:L18707. doi:10.1029/2006GL027232

> Nieto R, Gimeno L, Gallego D, Trigo R (2007) Contributions to the moisture budget of airmasses over Iceland. Meteorol Z 16:37-44

Nieto R, Gallego D, Trigo R, Ribera P, Gimeno L (2008) Dynamic identification of moisture sources in the Orinoco basin in equatorial South America. Hydrol Sci J 53: 602-617

Nieto R, Gimeno L, Drumond A, Hernandez E (2010) A Lagrangian identification of the main moisture sources and sinks affecting the Mediterranean area. Wseas Trans Environ Dev 5:365-374

Numaguti A (1999) Origin and recycling processes of precipitating water over the Eurasian continent: experiments using an atmospheric general circulation model. J Geophys Res 104:1957-1972

Ralph FM, Neiman PJ, Wick GA (2004) Satellite and CALJET aircraft observations of atmospheric rivers over the eastern North Pacific Ocean during the winter of 1997/98. Mon Weather Rev 132:1721-1745

Submitted: October 11, 2010; Accepted: December 29, 2010
Ramos AM, Lorenzo MN, Gimeno L (2010) Compatibility between modes of low-frequency variability and circulation types: a case study of the Northwest Iberian Peninsula. J Geophys Res 115:D02113. doi:10.1029/2009JD 012194

Sodemann H, Schwierz C, Wernli H (2008) Interannual variability of Greenland winter precipitation sources: Lagrangian moisture diagnostic and North Atlantic Oscillation influence. J Geophys Res 113:D03107. doi:10.1029/2007JD 008503

Stohl A (1998) Computation, accuracy and applications of trajectories - a review and bibliography. Atmos Environ 32: 947-966

Stohl A, James P (2004) A Lagrangian analysis of the atmospheric branch of the global water cycle, Part 1. Method description, validation, and demonstration for the August 2002 flooding in central Europe. J Hydrometeorol 5: $656-678$

Stohl A, James P (2005) A Lagrangian analysis of the atmospheric branch of the global water cycle, Part 2. Earth's river catchments, ocean basins, and moisture transports between them. J Hydrometeorol 6:961-984

Stohl A, Forster C, Frank A, Seibert P, Wotawa G (2005) Technical note: the Lagrangian particle dispersion model FLEXPART Version 6.2. Atmos Chem Phys 5:2461-2474

Trigo IF, Davies TD, Bigg GR (1999) Objective climatology of cyclones in the Mediterranean region. J Clim 12: 1685-1696

Uppala SM, Kållberg PW, Simmons AJ, Andrae U and others (2005) The ERA-40 re-analysis. Q J R Meteorol Soc 131: 2961-3012. doi:10.1256/qj.04.176

> Zhu Y, Newell RE (1998) A proposed algorithm for moisture fluxes from atmospheric rivers. Mon Weather Rev 126: $725-735$

Proofs received from author(s): August 12, 2011 